\title{
Self-cleaning building materials: the multifaceted effects of titanium dioxide
}

\author{
Riccardo Paolini ${ }^{1,2}$, Dario Borroni ${ }^{3}$, MariaPia Pedeferri ${ }^{3}$, Maria Vittoria Diamanti ${ }^{3}{ }^{3}$ \\ ${ }^{1}$ Politecnico di Milano, Department of Architecture, Built environment and Construction \\ engineering \\ ${ }^{2}$ The University of New South Wales, UNSW Built Environment \\ ${ }^{3}$ Politecnico di Milano, Department of Chemistry, Materials and Chemical Engineering "Giulio \\ Natta" \\ Corresponding author: Maria Vittoria Diamanti \\ Address: Politecnico di Milano, Department of Chemistry, Materials and Chemical Engineering \\ "Giulio Natta", Via Mancinelli 7, 20131 Milan, Italy \\ Email: mariavittoria.diamanti@polimi.it
}

Accepted for publication in

Construction and Building Materials

https://doi.org/10.1016/j.conbuildmat.2018.06.047

C2018. This manuscript version is made available under the CC-BY-NC-ND 4.0 license

http://creativecommons.org/licenses/by-nc-nd/4.0/

\begin{abstract}
Disclaimer
This document was prepared as an account of work in part sponsored by Politecnico di Milano \& Agenzia delle Entrate (Italian Revenue Agency). While this document is believed to contain correct information, neither the Italian Government nor any agency thereof, nor the Research Institutions to which the authors are affiliated, nor any of their employees, makes any warranty, express or implied, or assumes any legal responsibility for the accuracy, completeness, or usefulness of any information, apparatus, product, or process disclosed, or represents that its use would not infringe privately owned rights. Reference herein to any specific commercial product process, or service by its trade name, trademark, manufacturer, or otherwise, does not necessarily constitute or imply its endorsement, recommendation, or favoring by the Italian Government or any agency thereof, or the Research Institutions to which the authors are affiliated. The views and opinions of authors expressed herein do not necessarily state or reflect those of the Italian Government or any agency thereof, or their Research Institutions.
\end{abstract}




\begin{abstract}
The physical integrity and photocatalytic performance of titanium dioxide $\left(\mathrm{TiO}_{2}\right)$ deteriorate with aging. Here we propose a pre-treatment with nitric or sulfuric acid of commercial $\mathrm{TiO}_{2}$ nanopowders used in coating, mortars, or paints. The diffuse reflectance is increased between 1500 and $2500 \mathrm{~nm}$ by 0.04 and 0.06 , respectively, with nitric and sulfuric acid (unaffected by neutralization). Nitric acid causes a decrease in crystallinity and photocatalytic activity, which drops by almost $20 \%$; this drawback is prevented by post-treatment neutralization, which allows to recover initial photocatalytic efficiency and even increase it. Treatment with sulfuric acid shows no significant effect on photoactivity, instead.
\end{abstract}

Keywords: Acid treatment, photocatalysis, $\mathrm{P} 25$, self-cleaning, solar reflectance, $\mathrm{TiO}_{2}$

\title{
Highlights
}

- We treated anatase-rutile nano-powders with $\mathrm{HNO}_{3}$ or $\mathrm{H}_{2} \mathrm{SO}_{4}$.

- $\mathrm{HNO}_{3}$ decreases crystallinity and photoactivity (prevented by neutralization).

- Photoactivity and crystallinity are unaffected by $\mathrm{H}_{2} \mathrm{SO}_{4}$.

- $\mathrm{H}_{2} \mathrm{SO}_{4}$ increases the reflectance (1500-2500 nm) of paints with treated $\mathrm{TiO}_{2}$.

- This treatment can improve the performance over time of $\mathrm{TiO}_{2}$ added materials.

\section{Introduction}

Well before the discovery of its photocatalytic properties, titanium dioxide $\left(\mathrm{TiO}_{2}\right)$ has been used massively as a white pigment in textiles and paints [1], where in fact traces of its reactivity were perceived in the form of alterations of supporting materials - such as degradation of paints and fabrics, or bleaching of dyes. Still, the first scientific work on this subject dates back only to 1929 [2], suggesting an active role of $\mathrm{TiO}_{2}$ in the fading of paints. Eventually, the presence of active oxygen species detected on $\mathrm{TiO}_{2}$ surface was identified as cause of the photobleaching of dyes in presence of UV-irradiated $\mathrm{TiO}_{2}$ in the late 1930s [3], but the mechanisms of heterogeneous photocatalysis in presence of metal oxides were only described in the second half of XX century, and in the 1970s proofs of $\mathrm{TiO}_{2}$ photocatalytic activity were published [4,5]. Finally, in the 1990s, the self-cleaning effect of $\mathrm{TiO}_{2}$-containing materials was revealed [6]. Since then, large attention has been dedicated to the integration of this oxide in building materials, with possible positive consequences on the quality of the surrounding environment - i.e., cleaner air - and on the reduction of maintenance costs [7-9]. Several buildings have been designed to take advantage of $\mathrm{TiO}_{2}$ photocatalytic and self-cleaning activity, such as the Marunouchi Building (or Marubiru), in Tokyo, opened in 2002, one of the first buildings featuring self-cleaning window glasses, the jubilee church Dives in Misericordia, built in Rome in 2003, the Hospital Manuel Gea Gonzalez (Mexico City) completed in 2013, or the Italian pavilion at the Milano Expo 2015 Universal Exposition.

The applications of $\mathrm{TiO}_{2}$ containing building materials have been widening in the last years, going from the obtaining of self-cleaning façades [10-14] or roads [15-19] with added antipollution effects [20-23] to the development of preservation treatments for architectural heritage, especially 
in stone [24-28]. While the mechanisms of photocatalytic and self-cleaning activity have been long studied, together with the development of materials with improved photoactivated performance, their durability and the appraisal of the photoactivated effects over time, in real working conditions, remain only marginally treated. This is particularly true in the case of building materials used outdoors, where environmental agents such as rain, wind, pollution and microbiological growth may gradually deactivate the $\mathrm{TiO}_{2}$ component, or cause the degradation of the whole material by erosion or other physical mechanisms [11,12,29-32].

In more recent times, a further aspect related to the presence of $\mathrm{TiO}_{2}$ has been analyzed, which refers to its potential as cool pigment [33-36]. Cool surfaces do not overheat under the sun as they present a high solar reflectance, namely the ratio of reflected to incident solar radiation, and high thermal emittance, namely the ratio of emitted thermal radiation to that emitted by a black body. The use of cool materials for built surfaces, especially for roofing, minimizes the solar heat gains in buildings, reducing the cooling energy needs and peak power demand, and mitigate the local climate, reducing the heat released in the urban environment [37-41]. Since weathering and soiling can greatly reduce these benefits [41-44], recent building energy regulations, such as the Title 24 of the State of California, prescribe that non-residential roofs shall have a minimum aged solar reflectance (after three years) of 0.63 [45]. We recently demonstrated that anatase added materials suffer a less pronounced drop in solar reflectance upon environmental exposure $(0.19$ instead of 0.26 , after two years) [35]. In the second portion of the near-infrared wavelength range, namely between $1500 \mathrm{~nm}$ and $2500 \mathrm{~nm}$, as aging proceeds, the reflectance increases even in comparison to the freshly prepared material, which was ascribed to the material photocatalytic NOx degradation, responsible for the formation of nitric acid that alters the optical properties of the $\mathrm{TiO}_{2}$ nanoparticles (NPs) present in the material $[29,35]$.

This article presents a change in perspective with respect to the issue of self-cleaning $\mathrm{TiO}_{2}$ contaning materials with high solar reflectance. In fact, in the present study, $\mathrm{TiO}_{2} \mathrm{NPs}$ are modified to enhance their optical properties before adding them to the building material of interest, in this case, an acrylic paint. Two possible acid treatments are employed to this aim, i.e., with diluted nitric acid or sulfuric acid. Moreover, since these modified powders are envisioned as admixtures to construction materials (mortars, paints), with related handling issues, a final step of powders neutralization is also proposed and evaluated, to check whether modifications obtained by acid treatment are maintained also in neutralized powders. The $\mathrm{TiO}_{2}$-containing paint was then characterized from the point of view of its optical properties as well as its photocatalytic performance.

\section{Experimental}

\section{Samples preparation}

The passages followed to prepare $\mathrm{TiO}_{2}$ containing samples are summarized in Figure 1. The photocatalyst used in the preparation and study of paint samples is AEROXIDE® $\mathrm{TiO}_{2} \mathrm{P} 25$ by Evonik Industries. It contains a combination of anatase and rutile of about $80 \%-20 \%$ with purity $>99.5 \%$ and specific surface area of $35-65 \mathrm{~m}^{2} / \mathrm{g} .1 \mathrm{~g}$ of nanoparticles was first dispersed in $4 \mathrm{~g}$ of distilled water before incorporation into the paint, producing a suspension of $\mathrm{TiO}_{2}$ and distilled water with [1:4] ratio. Although an ultrasonic bath was used, the suspension still contained agglomerated nanoparticles and had a slightly milky appearance. Nitric acid and sulfuric acid were 
diluted $\left(0.5 \%\right.$ by weight for $\mathrm{HNO}_{3}$ and $0.1 \%$ for $\left.\mathrm{H}_{2} \mathrm{SO}_{4}\right)$ and $5 \mathrm{~g}$ of solution were added to the aqueous $\mathrm{TiO}_{2}$ suspension to perform an acid treatment of the NPs, which was shown to produce positive effects on their NIR reflectance [35]. A new solution was then obtained, containing $10 \%$ by weight of $\mathrm{TiO}_{2}$. The mixture was then evaporated on an electric plate at approximately $50{ }^{\circ} \mathrm{C}$, to reduce the water content before mixing with the paint, giving a total duration of the NPs-acid contact of $3 \mathrm{~h}$; the final $\mathrm{TiO}_{2}$ concentration was $33.3 \%\left(\mathrm{TiO}_{2}\right.$ :solvent in a ratio 1:2). In a latter formulation, after this interaction time and before incorporation in the paint, the mixture was also neutralized by adding a stoichiometric quantity of $\mathrm{NaOH}$ aqueous solution. Table 1 reports the sample labels as a function of the $\mathrm{TiO}_{2}$ nanoparticles treatment. Each composition was used to produce at least two samples to be used in optical measurements and two samples to be used in photocatalysis tests.

Since photocatalytic paints are commonly used in buildings to produce self-cleaning coatings, a white acrylic paint was chosen as support for $\mathrm{TiO}_{2}$ nanoparticles. We first tested the addition of the same diluted nitric acid solution, $0.5 \%$ by weight, to the paint, to verify if the incorporation of acid together with the nanoparticles could be detrimental to the paint itself, but no reaction was observed and a homogeneous mixture of paint and acid solution was obtained. The same was verified with sulfuric acid. It was therefore assumed that the acid contained in the NPs would not adversely affect the paint.

Fine quartz sand with $0.06-0.1 \mathrm{~mm}$ granulometry was used as a dimensional stabilizer, to produce homogeneous and crack-free thick samples of paint mixed with $\mathrm{TiO}_{2}$ suspension, as required for optical measurements performed in reflectance mode, where the sample thickness and opacity is essential to avoid light from being transmitted through the sample. The optimal ratio of $\mathrm{TiO}_{2}$, water (at the moment of the mixing), paint and sand was found to be 1:2:4:10, where each sample contains $6.67 \%$ by weight of $\mathrm{TiO}_{2}$. This is comparable to commercial coatings, which generally contain amounts of $\mathrm{TiO}_{2}$ that range from 1 to $10 \%$ by weight. Final samples containing sand had dimensions $30 \mathrm{~mm}$ x $60 \mathrm{~mm} \times 3 \mathrm{~mm}$.
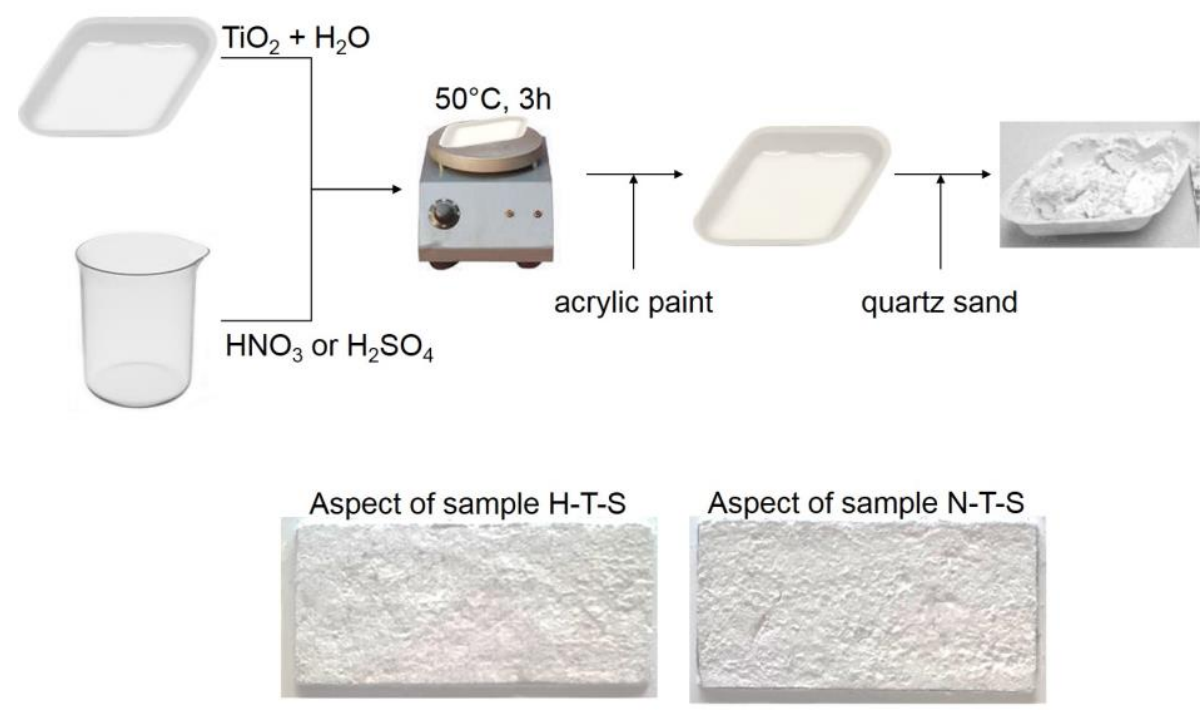

Figure 1 - Samples preparation steps and illustrative samples pictures. 
Table 1 - Samples labels and corresponding composition

\begin{tabular}{lccccc}
\hline Label & $\begin{array}{c}\mathbf{T i O}_{2} \text { particles } \\
\text { pre-immersion }\end{array}$ & $\begin{array}{c}\mathbf{T i O}_{2} \text { content } \\
(\% \text { by weight })\end{array}$ & $\begin{array}{c}\text { Paint content } \\
(\% \text { by weight })\end{array}$ & $\begin{array}{c}\text { Sand content } \\
(\% \text { by weight })\end{array}$ & $\begin{array}{c}\text { Neutralization } \\
\text { with NaOH }\end{array}$ \\
\hline Ref & - & - & 33.3 & 66.7 & - \\
\hline H-T & In DI $\mathrm{H}_{2} \mathrm{O}$ & 20 & 80 & - & - \\
H-T-S & & 6.67 & 26.7 & 66.7 & - \\
\hline N-T & & 20 & 80 & - & - \\
N-T-S & $\mathrm{In} \mathrm{HNO}_{3} 0.5 \mathrm{M}$ & 6.67 & 26.7 & 66.7 & - \\
N-TN-S & & 6.67 & 26.7 & 66.7 & Yes \\
\hline S-T & & 20 & 80 & - & - \\
S-T-S & $\mathrm{In}_{2} \mathrm{SO}_{4} 0.1 \mathrm{M}$ & 6.67 & 26.7 & 66.7 & - \\
S-TN-S & & 6.67 & 26.7 & 66.7 & Yes \\
\hline
\end{tabular}

\section{Characterization}

The crystallinity of P25 NPs, both acid-treated and further neutralized, was tested by means of X-ray diffraction spectrometry. A Philips PW 1830 instrument was employed, using $\mathrm{Cu} \mathrm{K} \alpha$ radiation ( $40 \mathrm{kV}$ applied tension, $0.5 \mathrm{deg} / \mathrm{min}$ scan rate). Particle morphology was analyzed by means of TEM analyses, which were performed with a Philips CM200 FEG (200 kV applied tension, electron wavelength $0.251 \AA, 0.19 \mathrm{~nm}$ resolution). Samples were prepared by depositing one drop of powder aqueous suspension on a copper grid coated with amorphous carbon and allowing it to dry before the analysis.

Before optical measurements, samples were allowed to dry for at least 14 days to achieve an equilibrium amount of water left in the material. This phase was particularly important to eliminate measurement errors related to different amounts of water contained in the samples, since water strongly affects reflectance in the whole light spectrum. UV-Vis-NIR reflectance measurements were carried out between 300 and $2500 \mathrm{~nm}$, with a spectral resolution of $5 \mathrm{~nm}$, with a Perkin Elmer Lambda 950 spectrometer, equipped with a $150 \mathrm{~mm}$ integrating sphere. The slit in the Vis range was set to $2 \mathrm{~nm}$ from 300 to $860 \mathrm{~nm}$, and in servo mode for the rest of the scan, with a characterized area of approximately $15 \mathrm{~mm}$ x $15 \mathrm{~mm}$ between 1500 and $2500 \mathrm{~nm}$. For each set of samples, three measurements per sample were performed on non-overlapping spots, and the average spectral curve computed.

Broadband values were then computed considering the solar spectral irradiance distribution for clear sky conditions and air mass equal to 1 [46]. $\rho_{\mathrm{s}}$ and $\rho_{\mathrm{n} 2}$ are, respectively, the solar reflectance and the broadband reflectance in the range between 1500 and $2500 \mathrm{~nm}$.

The photocatalytic activity of samples H-T and H-T-S, i.e., mixtures of non-treated $\mathrm{TiO}_{2}$ with only paint or paint and sand, was measured and compared, in order to verify the effect of sand addition on photoactivity. Then, the full characterization was performed on complete samples (paint, sand, and NPs). To check photocatalytic activity, rhodamine B - an azo dye with magenta hue - was chosen, as it is commonly accepted and utilized to test the efficiency of photocatalytic materials as representative of organic pollutants, as attested by several independent research groups $[14,29,31,47-50]$.

Samples were immersed in an aqueous solution of the dye with concentration $10^{-5} \mathrm{M}$ for $3 \mathrm{~h}$, dried and then exposed to artificial light simulating the solar spectrum (Osram Vitalux lamp, $300 \mathrm{~W}$ ) with UV intensity at $370 \mathrm{~nm}$ of $1 \mathrm{~mW} \mathrm{~cm}^{-2}$ for $4 \mathrm{~h}$. All samples were characterized in 
double, conducting simultaneously measurements on one sample per type of material: UV irradiation at $365 \mathrm{~nm}$ was set at the same intensity in each spot utilized for the tests by means of a radiometer UM-10 by Konica Minolta. Their color before and after irradiation was measured by reflectance spectrophotometry, using a Konica Minolta CM-2600d spectrophotometer. The software Spectramagic NX was then used to convert reflectance information into color coordinates $\mathrm{L}^{*} \mathrm{a}^{*} \mathrm{~b}^{*}$ in the color space CIELab, as defined by the Commission Intérnationale de l'Éclairage [51]. Rhodamine B degradation was correlated to the decrease in the $\mathrm{a}^{*}$ (red) coordinate of color, representing a loss of intensity in red and therefore a discoloration of the dye.

\section{Results and discussion}

Sample preparation required a careful adjustment of mix parameters in order to achieve a crack-free, thick sample suitable for optical measurements, where the presence of cracks may cause differential optical penetration depths over the surface of the specimen, altering its optical response. For this reason, all measurements of UV-Vis-NIR reflectance were performed on the sandcontaining specimens (labels ending with $S$ ).

Figure 2 summarizes the results of UV-Vis-NIR measurements on reference samples (paint+sand, with no $\mathrm{TiO}_{2}$ admixture or with non-modified $\mathrm{TiO}_{2}$ ), on samples containing acidtreated $\mathrm{TiO}_{2}$ nanoparticles (Fig. 2a) and on samples produced with nanoparticles that were first acid treated, and then neutralized with stoichiometric $\mathrm{NaOH}$ before mixing with paint (Fig. 2b).
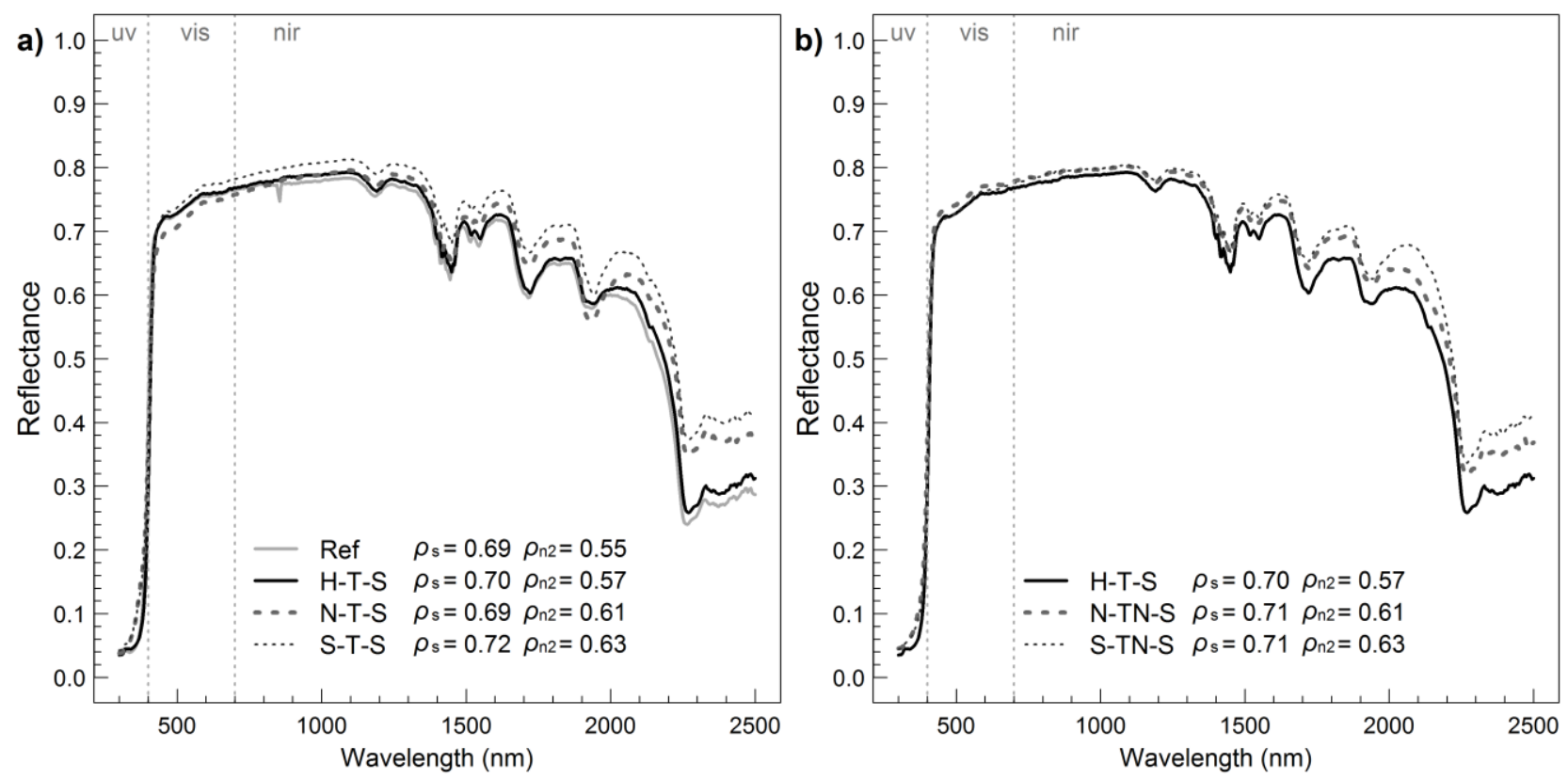

Figure 2 - UV-Vis-NIR measurements on samples produced by mixing $\mathrm{TiO}_{2} \mathrm{NPs}$, either acidtreated or not, with an acrylic paint and quartz sand. Left: reference samples (only paint+sand, Ref, and with non-modified $\mathrm{TiO}_{2}, \mathrm{H}-\mathrm{T}$ ) and acid-treated NPs; right: acid-treated and then neutralized NPs (with H-T-S for easier comparison).

A first observation concerns the effect of $\mathrm{TiO}_{2} \mathrm{P} 25$ addition to the paint and sand mixture, which produces a negligible effect on solar reflectance, as attested by the similar positions of curves Ref and H-T. This is due to the presence of rutile as white pigment in the paint base formulation, which already ensures a high reflectance, especially in the visible spectral region. The choice of 
mixing P25 nanoparticles with a paint was indeed due to several reasons, as it provides: easier binding of nanoparticles to avoid dispersion and possible operator health issues; a material where $\mathrm{TiO}_{2}$ admixtures find common application; and a material that already contains pigmentary $\mathrm{TiO}_{2}$. In this way, differences observed in samples containing acid-treated powders would only be due to the P25 powders properties, while any possible influence of $\mathrm{TiO}_{2}$-matrix interactions on optical or photocatalytic properties would already be accounted for, both in the reference and in the modified material, thanks to the presence of pigmentary $\mathrm{TiO}_{2}$.

As already proved [35], the acid treatment increases reflectance. While in the cited previous study the powder analyses, from a morphological and optical point of view, were made only on $\mathrm{TiO}_{2} \mathrm{NPs}$, this time a complex material is proposed, suitable for real applications in terms of composition and $\mathrm{TiO}_{2}$ content, and the effect of NIR reflectance increase is actually maintained. Computing the broadband reflectance in the wavelength range between 1500 and $2500 \mathrm{~nm}$, an increase by 0.04 and 0.06 in reflectance, namely by $7 \%$ and $11 \%$, is obtained when NPs are treated with nitric acid and sulfuric acid, respectively, with respect to water treated samples. These differences largely exceed the measurement uncertainty due to repeatability, as previously observed [35]. This improvement is mostly maintained when NPs are neutralized before mixing with paint and sand, with only small losses at the longest wavelengths on $\mathrm{HNO}_{3}$ treated NPs: it is then possible to assume that the optical effect is not only due to the direct contact with acid but is maintained once NPs are prepared for use in building materials, where the use of strong acids is not recommended.

Although the increase in solar reflectance for N-TN-S and S-TN-S samples is modest, the effect in the $1500-2500 \mathrm{~nm}$ wavelength range, a spectral region typically unaffected by weathering and soiling, can prove useful to retain over time the optical performance as much as possible. For the samples treated with $\mathrm{H}_{2} \mathrm{SO}_{4}$, the NIR reflectance is increased to 0.77 ( 0.75 for the water treated samples), while for the samples treated with $\mathrm{HNO}_{3}$ there is no change.

Interestingly, the visual aspect of the materials produced with the differently treated NPs did not undergo any variation, as attested by the overlapping of reflectance spectra in the visible light range, also shown in Figure 2. This aspect is also important, in order to guarantee the correct façade visual conditions from the material production stage, thus providing an admixture with improved NIR reflectance behavior but unaltered visual properties.

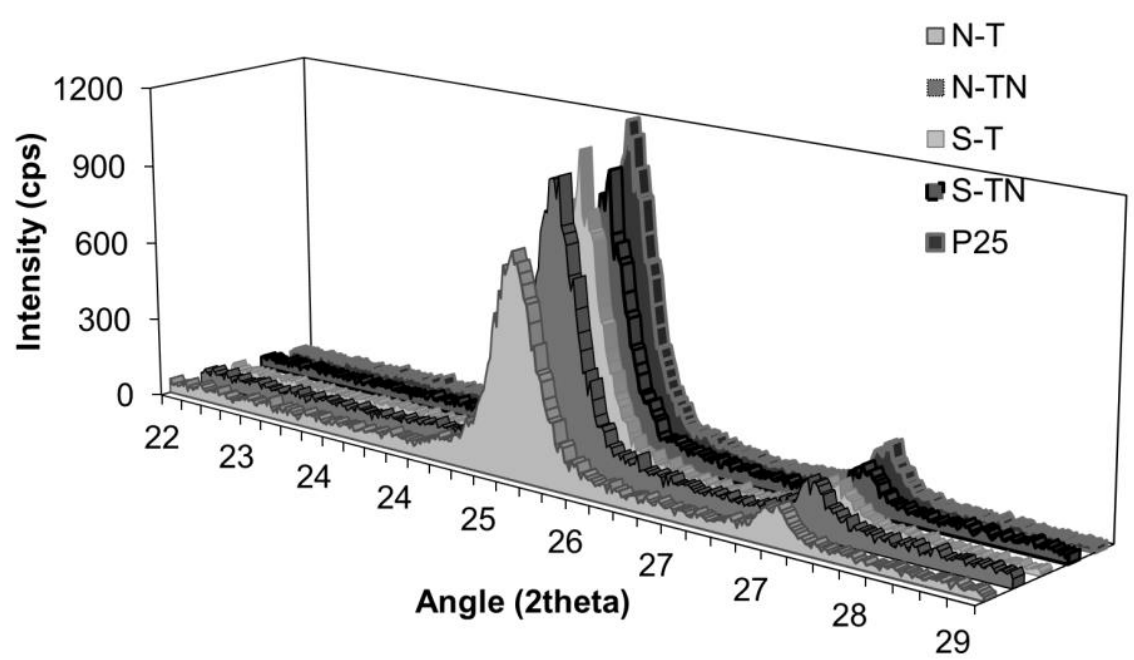

Figure 3 - XRD spectra of P25 powders before treatment, after acid treatment and after neutralization. Labels recall Table 1 although samples do not contain paint. 
Results of XRD measurements are reported in Figure 3. Tests were performed on $\mathrm{TiO}_{2} \mathrm{NPs}$ without any paint or sand added, to avoid loss of information due to the presence of rutile white pigments in the paint. The slight shift in anatase peak position $\left(25.3^{\circ}\right.$ to $\left.25.4^{\circ}\right)$ in acid treated samples compared to P25 is so small that it may be considered negligible; even considering it relevant, it may be attributed to defects created by the acids and/or impurities remaining on the particles surface, which is in agreement with previous observations [35]. Immersion in nitric acid causes a decrease in NPs crystallinity that is associated with a decrease in intensity of the anatase peak at $25.2^{\circ}$. This could be ascribed to an amorphization of NPs, which may interest the whole nanoparticle volume or, most likely, be limited to its surface. Indeed, neutralization apparently restores the initial crystallinity condition. This supports our previous hypothesis that nitric acid acts on the particles surface creating disorder by protonation and hydroxylation, while its neutralization with $\mathrm{NaOH}$ is sufficient to partially restore the nanoparticles surface structure and therefore the observed crystallinity. On the other hand, sulfuric acid has no relevant effect on oxide crystallinity. These observations are of great importance if correlated with UV-Vis-NIR analyses. In fact, $\mathrm{H}_{2} \mathrm{SO}_{4}$ is able to increase the reflectance of P25-containing materials in the near infrared wavelength region to a greater extent with respect to $\mathrm{HNO}_{3}$ and without modifying the NPs crystallinity, thus presenting a more beneficial overall effect compared with nitric acid.

To further investigate the characteristics of acid-treated particles and correlate them to their optical and photocatalytic behavior, TEM analyses were performed. Results are summarized in Table 2, where both bright field and dark field images of the nanoparticles are reported. Only in the case of nitric acid-treated powders (sample N-T) a variation of particles aspect was noticed, i.e., a blurring of the external particle surface. A statistical analysis was performed on several images, comparing the size of same particles appearing in both bright field and dark field images - i.e., comparing particle actual morphology (bright field) and the dimension of the crystallite composing the particle (dark field), on a minimum of 50 particles per material. This analysis showed that only for nanoparticles immersed in nitric acid an average decrease in corresponding crystallite size of 2 $\mathrm{nm}$ was observed, indicating the presence of an amorphous layer around the particle, while no change was found in the other materials: this further supports XRD results, which indicate a lower crystallinity of the N-T sample. As previously proposed, and supported by further research works, the amorphization is ascribed to surface protonation of the oxide in acid environment $[35,52,53]$.

Table 2 - TEM analyses of P25 powders before treatment, after acid treatment and after neutralization (labels recall Table 1 although samples do not contain paint) and difference between TEM bright field and dark field particle size, corresponding to the difference between actual particle size and size of corresponding crystal domain. Uncertainties are calculated as standard deviation of the set of measurements. 


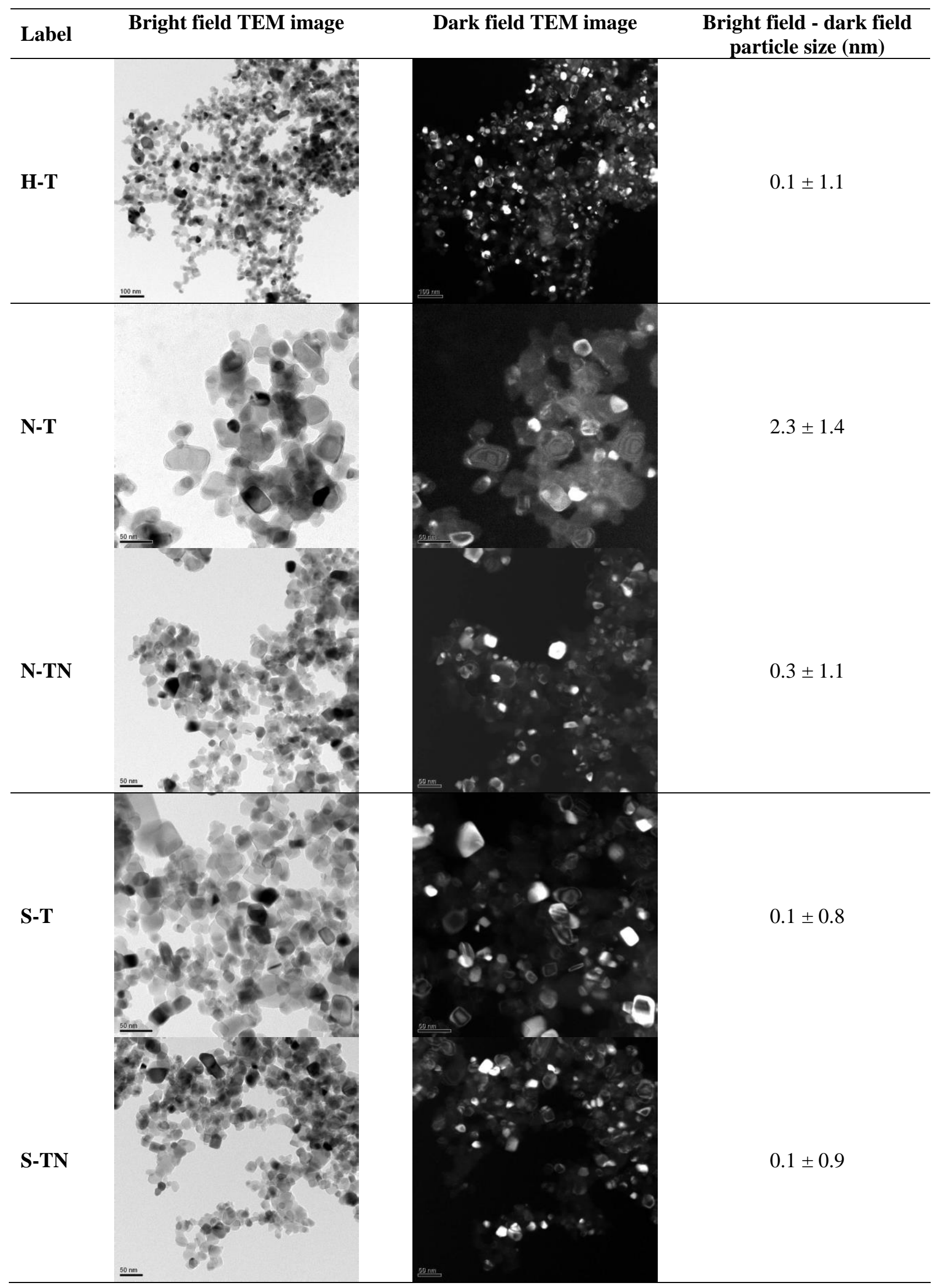


Photocatalysis tests were performed both on simple paint samples and on those containing the volume stabilizing sand admixture. This first evaluation was performed on all samples; results concerning non-treated $\mathrm{TiO}_{2}$ powders are shown as an example in Figure 4, but the same considerations apply to acid treated powders. Data reported are related to the percent decrease in $\mathrm{a}^{*}$ coordinate intensity, which can be taken as an indirect measurement of dye degradation percentage [50]. The effect of sand is that of magnifying the photocatalytic efficiency of $\mathrm{TiO}_{2} \mathrm{NPs}$ : this was ascribed to possible beneficial effects of better powder dispersion and refraction of light within the layer of sand-admixed paint with respect to NPs dispersed in the paint. In fact, in presence of sand the paint, which may shield $\mathrm{TiO}_{2}$, is present in lower content; moreover, $\mathrm{TiO}_{2}$ addition can better distribute over the surface of quartz granules, which in turn do not absorb UV light but rather scatter the portion of it that is not absorbed by $\mathrm{TiO}_{2}$, allowing it to reach other $\mathrm{TiO}_{2}$ nanoparticles. Eventually, also surface roughness may play a role, being sand-containing samples rougher than paint alone, which could make available a larger number of active sites for the photocatalytic reactions.

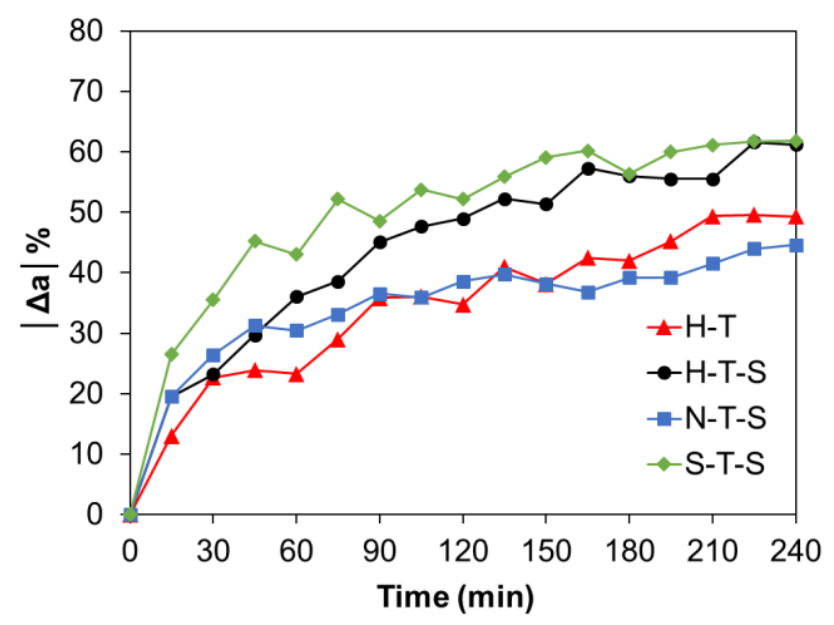

Figure 4 - Percent decrease in a* coordinate in presence of samples prepared with $\mathrm{TiO}_{2} \mathrm{P} 25 \mathrm{NPs}$ dispersed in acrylic paint (H-T) or in samples with the addition of quartz sand: acid-treated NPs vs non-treated ones.

On the other hand, acid treatment showed a strong influence on NPs photoactivity. In fact, results plotted in Figure 4 indicate a decrease in photocatalytic efficiency when nitric acid is used to modify the NPs. Conversely, sulfuric acid does not exert a relevant effect and the NPs efficiency remains unaltered with respect to original P25. This was ascribed to the previously cited effects of nitric acid of decreasing NPs crystallinity and causing nitrates adsorption on the NPs surface, which may poison them.

Interestingly, if NPs are neutralized before adding them to the samples (Figure 5), this poisoning effect is eliminated, and NPs acquire even higher efficiency than initial $\mathrm{TiO}_{2} \mathrm{P} 25$. On the other hand, after observing the absence of effects of $\mathrm{H}_{2} \mathrm{SO}_{4}$ treatment on NPs photocatalytic efficiency, likewise its neutralization also does not lead to a significant variation of their photocatalytic properties. 


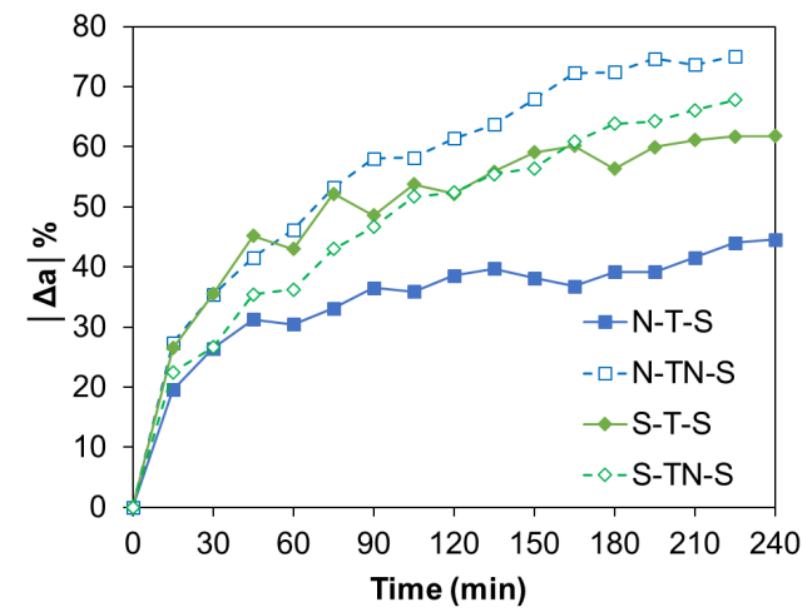

Figure 5 - Percent decrease in a* coordinate in presence of samples prepared with $\mathrm{TiO}_{2} \mathrm{P} 25 \mathrm{NPs}$ dispersed in acrylic paint with the addition of quartz sand: effect of NPs neutralization before samples preparation.

Figure 6 provides a comparison among the materials tested in terms of both solar reflectance and photocatalytic efficiency. Data are calculated as percent variation of the performance with respect to materials produced with non-treated $\mathrm{TiO}_{2} \mathrm{P} 25 \mathrm{NPs}$. As for photoactivity, the average variation in $\mathrm{RhB}$ percent degradation at the final test duration $(4 \mathrm{~h})$ was chosen as parameter, in order to reduce the impact of small-time-scale fluctuations typical of single color measurements on non-uniform surfaces, while to evaluate optical properties in the NIR range the broadband reflectance in the 1500-2500 nm wavelength range was considered. From this summary, it is clear that sulfuric acid treatment of powders allows an improvement in both optical properties and photocatalytic efficiency, increasing the whole NIR reflectance and Rhodamine B degradation extent; NPs neutralization is in this case uninfluential with respect to the material functional properties, it only maintains the role of allowing easier powders handling. On the other hand, if nitric acid is used, NPs experience a smaller improvement in the NIR spectral region- almost half of that observed with sulfuric acid - and photocatalytic activity decreases by a large amount. The latter inconvenient aspect is recovered with NPs neutralization, actually reaching an increase in dye degradation compared to the initial $\mathrm{TiO}_{2} \mathrm{P} 25$ performances. Hence, both acids may be taken into consideration to produce $\mathrm{TiO}_{2}$ cool pigments by acid treatment of commercial $\mathrm{TiO}_{2}$ powders. Still, the overall behavior ensured by sulfuric acid treatment is less dependent on the full production cycle: it allows to improve optical and functional properties of $\mathrm{TiO}_{2}$-admixed materials to a large extent, and still to preserve these improvements in case NPs neutralization is needed for safety or material durability purposes, representing therefore a more reliable choice of treatment. 


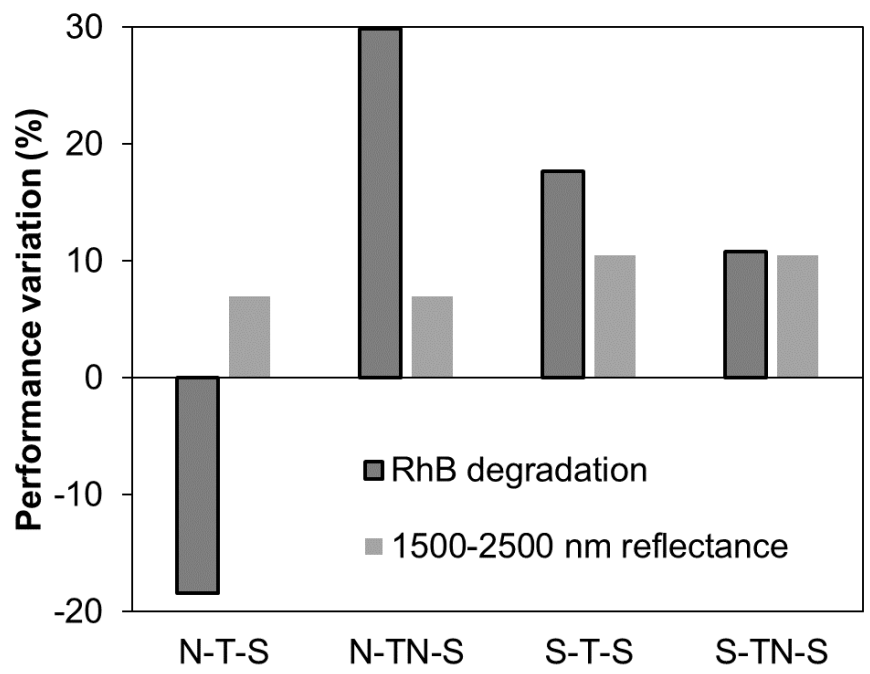

Figure 6 - Percent variation in the two main properties investigated, i.e., photocatalytic efficiency (RhB degradation extent) and reflectance computed in the range $1500-2500 \mathrm{~nm}$, as a function of the treatment undergone by $\mathrm{TiO}_{2} \mathrm{NPs}$.

\section{Conclusions}

This work investigated the possibility of modifying $\mathrm{TiO}_{2}$ nanoparticles optical properties, aiming at improving the energy and environmental performance of self-cleaning building materials that contain such compounds. In previous evaluations by our research group [35] acid treatment was performed on the final building material (mortar or bituminous membrane) to understand the origin of the NIR reflectance alteration observed outdoor: in this context, diluted sulfuric acid was discarded, as it affected also the aesthetical appearance of the matrix to which $\mathrm{TiO}_{2}$ was added to a greater extent with respect to what observed in natural exposure. We here demonstrate that a pretreatment of powders by either nitric acid or sulfuric acid can be performed without aesthetic issues if powders are treated before being added to the matrix material (e.g. mortars or paints). Indeed, the acid treatment is not considered hazardous towards the final matrix or substrate in which the $\mathrm{TiO}_{2}$ will be admixed or applied on. Moreover, a neutralization step is also proposed, which is aimed at decreasing handling issues of acid-treated nanoparticles. Tests showed a better reliability of the sulfuric acid treatment, which ensures improvements in NIR reflectance while avoiding undesired decreases in photocatalytic efficiency. This makes $\mathrm{H}_{2} \mathrm{SO}_{4}$ the best candidate for $\mathrm{TiO}_{2}$ nanoparticles acid treatment with the aim of improving both their reflectance in a wavelength region unaffected by aging and sustaining their photocatalytic activity over time.

\section{Acknowledgements}

This work was in part supported by Politecnico di Milano \& Agenzia delle Entrate (Italian Revenue Agency) with the project "Cinque per mille junior - Rivestimenti fluorurati avanzati per superfici edilizie ad alte prestazioni”.

\section{References}

[1] A. Khataee, G.A. Mansoori, Nanostructured Titanium Dioxide Materials, World Scientific Publishing Co., Singapore, 2011. http://www.worldscientific.com/worldscibooks/10.1142/8325 (accessed December 14, 2016).

[2] E. Keidel, Die Beeinflussung der Lichtechtheit von Teerfarblacken durch Titanweiss [Influence of titanium white on the fastness to light of coal-tar days], Farben-Ztg. 34 (1929) 1242-1243. 
[3] C.F. Goodeve, J.A. Kitchener, Photosensitisation by titanium dioxide, Trans. Faraday Soc. 34 (1938) $570-579$. doi:10.1039/TF9383400570.

[4] W. Doerffler, K. Hauffe, Heterogeneous photocatalysis I. The influence of oxidizing and reducing gases on the electrical conductivity of dark and illuminated zinc oxide surfaces, J. Catal. 3 (1964) 156-170. doi:10.1016/00219517(64)90123-X.

[5] A. Fujishima, K. Honda, Electrochemical Photolysis of Water at a Semiconductor Electrode, Nature. 238 (1972) 37-38. doi:10.1038/238037a0.

[6] R. Wang, K. Hashimoto, A. Fujishima, M. Chikuni, E. Kojima, A. Kitamura, M. Shimohigoshi, T. Watanabe, Light-induced amphiphilic surfaces, Nature. 388 (1997) 431-432. doi:10.1038/41233.

[7] M.V. Diamanti, M. Pedeferri, Concrete, mortar and plaster using titanium dioxide nanoparticles: applications in pollution control, self-cleaning and photo sterilization, in: Nanotechnol. Eco-Effic. Constr., Elsevier, 2013: pp. 299-326. http://linkinghub.elsevier.com/retrieve/pii/B9780857095442500130 (accessed January 15, 2016).

[8] A. Fujishima, X. Zhang, D. Tryk, Heterogeneous photocatalysis: From water photolysis to applications in environmental cleanup, Int. J. Hydrog. Energy. 32 (2007) 2664-2672. doi:10.1016/j.ijhydene.2006.09.009.

[9] K. Nakata, A. Fujishima, TiO2 photocatalysis: Design and applications, J. Photochem. Photobiol. C Photochem. Rev. 13 (2012) 169-189. doi:10.1016/j.jphotochemrev.2012.06.001.

[10] A. Folli, C. Pade, T.B. Hansen, T. De Marco, D.E. Macphee, TiO2 photocatalysis in cementitious systems: Insights into self-cleaning and depollution chemistry, Cem. Concr. Res. 42 (2012) 539-548. doi:10.1016/j.cemconres.2011.12.001.

[11] L. Graziani, E. Quagliarini, F. Bondioli, M. D’Orazio, Durability of self-cleaning TiO2 coatings on fired clay brick façades: Effects of UV exposure and wet \& dry cycles, Build. Environ. 71 (2014) 193-203. doi:10.1016/j.buildenv.2013.10.005.

[12] M. Baudys, J. Krýsa, M. Zlámal, A. Mills, Weathering tests of photocatalytic facade paints containing ZnO and TiO2, Chem. Eng. J. 261 (2015) 83-87. doi:10.1016/j.cej.2014.03.112.

[13] S. Banerjee, D.D. Dionysiou, S.C. Pillai, Self-cleaning applications of TiO2 by photo-induced hydrophilicity and photocatalysis, Appl. Catal. B Environ. 176-177 (2015) 396-428. doi:10.1016/j.apcatb.2015.03.058.

[14] M.-Z. Guo, A. Maury-Ramirez, C.S. Poon, Self-cleaning ability of titanium dioxide clear paint coated architectural mortar and its potential in field application, J. Clean. Prod. 112, Part 4 (2016) 3583-3588. doi:10.1016/j.jclepro.2015.10.079.

[15] M. M. Hassan, Quantification of the Environmental Benefits of Ultrafine/Nanotitanium Dioxide Photocatalyst Coatings for Concrete Pavement Using Hybrid Life-Cycle Assessment, J. Infrastruct. Syst. 16 (2010) 160-166. doi:10.1061/(ASCE)IS.1943-555X.0000016.

[16] C.S. Poon, E. Cheung, NO removal efficiency of photocatalytic paving blocks prepared with recycled materials, Constr. Build. Mater. 21 (2007) 1746-1753. doi:10.1016/j.conbuildmat.2006.05.018.

[17] M.M. Ballari, H.J.H. Brouwers, Full scale demonstration of air-purifying pavement, J. Hazard. Mater. 254-255 (2013) 406-414. doi:10.1016/j.jhazmat.2013.02.012.

[18] C. Toro, B.T. Jobson, L. Haselbach, S. Shen, S.H. Chung, Photoactive roadways: Determination of CO, NO and VOC uptake coefficients and photolabile side product yields on $\mathrm{TiO} 2$ treated asphalt and concrete, Atmos. Environ. 139 (2016) 37-45. doi:10.1016/j.atmosenv.2016.05.007.

[19] E. Boonen, A. Beeldens, Photocatalytic roads: from lab tests to real scale applications, Eur. Transp. Res. Rev. 5 (2013) 79-89. doi:10.1007/s12544-012-0085-6.

[20] J. Chen, C.-S. Poon, Photocatalytic activity of titanium dioxide modified concrete materials - Influence of utilizing recycled glass cullets as aggregates, J. Environ. Manage. 90 (2009) 3436-3442. doi:10.1016/j.jenvman.2009.05.029.

[21] M.-Z. Guo, A. Maury-Ramirez, C.S. Poon, Photocatalytic activities of titanium dioxide incorporated architectural mortars: Effects of weathering and activation light, Build. Environ. 94, Part 1 (2015) 395-402. doi:10.1016/j.buildenv.2015.08.027.

[22] C. George, A. Beeldens, F. Barmpas, J.-F. Doussin, G. Manganelli, H. Herrmann, J. Kleffmann, A. Mellouki, Impact of photocatalytic remediation of pollutants on urban air quality, Front. Environ. Sci. Eng. 10 (2016) 2. doi:10.1007/s11783-016-0834-1.

[23] N. Bengtsson, M. Castellote, Photocatalytic Activity for NO Degradation by Construction Materials: Parametric Study and Multivariable Correlations, J. Adv. Oxid. Technol. 13 (2010) 341-349.

[24] P. Munafò, G.B. Goffredo, E. Quagliarini, TiO2-based nanocoatings for preserving architectural stone surfaces: An overview, Constr. Build. Mater. 84 (2015) 201-218. doi:10.1016/j.conbuildmat.2015.02.083.

[25] D. Colangiuli, A. Calia, N. Bianco, Novel multifunctional coatings with photocatalytic and hydrophobic properties for the preservation of the stone building heritage, Constr. Build. Mater. 93 (2015) $189-196$. doi:10.1016/j.conbuildmat.2015.05.100.

[26] E. Quagliarini, F. Bondioli, G.B. Goffredo, A. Licciulli, P. Munafò, Smart surfaces for architectural heritage: Preliminary results about the application of TiO2-based coatings on travertine, J. Cult. Herit. 13 (2012) $204-209$. doi:10.1016/j.culher.2011.10.002. 
[27] E. Quagliarini, F. Bondioli, G.B. Goffredo, A. Licciulli, P. Munafò, Self-cleaning materials on Architectural Heritage: Compatibility of photo-induced hydrophilicity of $\mathrm{TiO} 2$ coatings on stone surfaces, J. Cult. Herit. 14 (2013) 1-7. doi:10.1016/j.culher.2012.02.006.

[28] L. Pinho, M. Rojas, M.J. Mosquera, Ag-SiO2-TiO2 nanocomposite coatings with enhanced photoactivity for self-cleaning application on building materials, Appl. Catal. B Environ. 178 (2015) 144-154. doi:10.1016/j.apcatb.2014.10.002.

[29] M.V. Diamanti, R. Paolini, M. Rossini, A.B. Aslan, M. Zinzi, T. Poli, M.P. Pedeferri, Long term self-cleaning and photocatalytic performance of anatase added mortars exposed to the urban environment, Constr. Build. Mater. 96 (2015) 270-278. doi:10.1016/j.conbuildmat.2015.08.028.

[30] M.V. Diamanti, M. Ormellese, M. Pedeferri, Characterization of photocatalytic and superhydrophilic properties of mortars containing titanium dioxide, Cem. Concr. Res. 38 (2008) 1349-1353. doi:10.1016/j.cemconres.2008.07.003.

[31] A. Calia, M. Lettieri, M. Masieri, Durability assessment of nanostructured TiO2 coatings applied on limestones to enhance building surface with self-cleaning ability, Build. Environ. 110 (2016) 1-10. doi:10.1016/j.buildenv.2016.09.030.

[32] D. Osborn, M. Hassan, S. Asadi, J. White, Durability Quantification of TiO2 Surface Coating on Concrete and Asphalt Pavements, J. Mater. Civ. Eng. 26 (2013) 331-337. doi:10.1061/(ASCE)MT.1943-5533.0000816.

[33] A.P. Werle, M.L. de Souza, K. Loh, R. Ando, V.M. John, The performance of a self-cleaning cool cementitious surface, Energy Build. 114 (2016) 200-205. doi:10.1016/j.enbuild.2015.06.025.

[34] R. Sharma, R. Shaw, S. Tiwari, S. Tiwari, Nano-Titania Decorated Fly Ash as Self-Cleaning Antibacterial Cool Pigment, ACS Sustain. Chem. Eng. 3 (2015) 2796-2803. doi:10.1021/acssuschemeng.5b00692.

[35] R. Paolini, M. Sleiman, M. Pedeferri, M.V. Diamanti, TiO2 alterations with natural aging: Unveiling the role of nitric acid on NIR reflectance, Sol. Energy Mater. Sol. Cells. 157 (2016) 791-797. doi:10.1016/j.solmat.2016.07.052.

[36] S. Wang, J. Zhang, L. Liu, F. Yang, Y. Zhang, Evaluation of cooling property of high density polyethylene (HDPE)/titanium dioxide (TiO2) composites after accelerated ultraviolet (UV) irradiation, Sol. Energy Mater. Sol. Cells. 143 (2015) 120-127. doi:10.1016/j.solmat.2015.06.032.

[37] M. Santamouris, Cooling the buildings - past, present and future, Energy Build. 128 (2016) 617-638. doi:10.1016/j.enbuild.2016.07.034.

[38] H. Akbari, C. Cartalis, D. Kolokotsa, A. Muscio, A.L. Pisello, F. Rossi, M. Santamouris, A. Synnefa, N.H. Wong, M. Zinzi, Local climate change and urban heat island mitigation techniques - the state of the art, J. Civ. Eng. Manag. 22 (2016) 1-16. doi:10.3846/13923730.2015.1111934.

[39] R. Levinson, P. Berdahl, A. Asefawberhe, H. Akbari, Effects of soiling and cleaning on the reflectance and solar heat gain of a light-colored roofing membrane, Atmos. Environ. 39 (2005) 7807-7824. doi:10.1016/j.atmosenv.2005.08.037.

[40] H. Akbari, R. Levinson, L. Rainer, Monitoring the energy-use effects of cool roofs on California commercial buildings, Energy Build. 37 (2005) 1007-1016. doi:10.1016/j.enbuild.2004.11.013.

[41] R. Paolini, M. Zinzi, T. Poli, E. Carnielo, A.G. Mainini, Effect of ageing on solar spectral reflectance of roofing membranes: Natural exposure in Roma and Milano and the impact on the energy needs of commercial buildings, Energy Build. 84 (2014) 333-343. doi:10.1016/j.enbuild.2014.08.008.

[42] M. Sleiman, G. Ban-Weiss, H.E. Gilbert, D. François, P. Berdahl, T.W. Kirchstetter, H. Destaillats, R. Levinson, Soiling of building envelope surfaces and its effect on solar reflectance-Part I: Analysis of roofing product databases, Sol. Energy Mater. Sol. Cells. 95 (2011) 3385-3399. doi:10.1016/j.solmat.2011.08.002.

[43] P. Berdahl, H. Akbari, R. Levinson, W.A. Miller, Weathering of roofing materials - An overview, Constr. Build. Mater. 22 (2008) 423-433. doi:10.1016/j.conbuildmat.2006.10.015.

[44] P. Berdahl, H. Akbari, L.S. Rose, Aging of reflective roofs: soot deposition, Appl. Opt. 41 (2002) 2355-2360.

[45] California Energy Commission, 2016 Building Energy Efficiency Standards for Residential and Nonresidential Buildings - Title 24, Part 6, (2015). http://www.energy.ca.gov/title24/2016standards/ (accessed July 11, 2017).

[46] R. Levinson, H. Akbari, P. Berdahl, Measuring solar reflectance-Part I: Defining a metric that accurately predicts solar heat gain, Sol. Energy. 84 (2010) 1717-1744. doi:10.1016/j.solener.2010.04.018.

[47] I.K. Konstantinou, T.A. Albanis, TiO2-assisted photocatalytic degradation of azo dyes in aqueous solution: kinetic and mechanistic investigations, Appl. Catal. B Environ. 49 (2004) 1-14. doi:10.1016/j.apcatb.2003.11.010.

[48] J. Zhang, S. Yan, L. Fu, F. Wang, M. Yuan, G. Luo, Q. Xu, X. Wang, C. Li, Photocatalytic Degradation of Rhodamine B on Anatase, Rutile, and Brookite TiO2, Chin. J. Catal. 32 (2011) 983-991. doi:10.1016/S18722067(10)60222-7.

[49] T. Wu, G. Liu, J. Zhao, H. Hidaka, N. Serpone, Photoassisted Degradation of Dye Pollutants. V. SelfPhotosensitized Oxidative Transformation of Rhodamine B under Visible Light Irradiation in Aqueous TiO2 Dispersions, J. Phys. Chem. B. 102 (1998) 5845-5851. doi:10.1021/jp980922c.

[50] M.V. Diamanti, F. Lollini, M.P. Pedeferri, L. Bertolini, Mutual interactions between carbonation and titanium dioxide photoactivity in concrete, Build. Environ. 62 (2013) 174-181. doi:10.1016/j.buildenv.2013.01.023. 
[51] R.W.G. Hunt, The Specification of Colour Appearance. I. Concepts and Terms, Color Res. Appl. 2 (1977) 55-68. doi:10.1002/col.5080020202.

[52] L.K. Dhandole, M.A. Mahadik, S.-G. Kim, H.-S. Chung, Y.-S. Seo, M. Cho, J.H. Ryu, J.S. Jang, Boosting Photocatalytic Performance of Inactive Rutile TiO2 Nanorods under Solar Light Irradiation: Synergistic Effect of Acid Treatment and Metal Oxide Co-catalysts, ACS Appl. Mater. Interfaces. 9 (2017) 23602-23613. doi:10.1021/acsami.7b02104.

[53] J. Soria, J. Sanz, M.J. Torralvo, I. Sobrados, C. Garlisi, G. Palmisano, S. Çetinkaya, S. Yurdakal, V. Augugliaro, The effect of the surface disordered layer on the photoreactivity of titania nanoparticles, Appl. Catal. B Environ. 210 (2017) 306-319. doi:10.1016/j.apcatb.2017.03.045. 